\title{
Strategies of absolute pitch possessors in the learning of an unfamiliar scale
}

\author{
KATIIRYN E. EATON and MICHAEL H. SIEGEL \\ State (Iniversity of New York, Onconta, New York 13820
}

\begin{abstract}
Possessors of absolute pitch and control subjects were trained and later tested to identify pitches labeled with arbitrary note names. Although the absolute pitch subjects learned better than the controls, there was no difference in learning rate. Results are discussed in terms of sensory memory and category availability.
\end{abstract}

A small percentage of the population is able to identify and reproduce musical pitches with a very high degree of accuracy. This ability is known as absolute pitch (AP), or perfect pitch, as musicians prefer to call it. AP is generally an asset to a musician because it helps in playing an instrument in tune, in sight-singing easily and accurately, and in knowing what a piece of music will sound like simply by reading the musical score.

Most theories of AP that have been formulated imply that, although it may be an inborn ability, it is more likely acquired and developed through musical training and experience. Cuddy $(1968,1970,1971)$ has developed methods for the systematic training of AP and has produced results which support the acquisition-throughtraining hypothesis. Her subjects were able to learn and remember the names of pitches accurately, especially when training included teaching them a reference tone first. She theorized, therefore, that AP subjects have internalized a reference tone or set of tones and use them for comparison with incoming pitch stimuli.

Another recent theory concerned with AP has been proposed by Siegel (1972, 1974; Siegel \& Siegel, 1972). She proposed that AP possessors have encoding strategies for pitch that are, in effect, similar to those employed in verbal learning and retention. AP possessors use the verbal labels of the Western musical scale, (e.g. A, A\#, B) as categorical definitions and, upon hearing an auditory stimulus, are able to place it into its appropriate category, thereby associating it with its verbal label. In one of these studies (Siegel, 1974), it was found that AP possessors were superior to controls only when the stimuli were separated by either .75 semitone or a full semitone, as compared with a .10-semitone condition. It was apparent, therefore, that the AP subjects needed a verbal labeling system and adequate frequency separations in order to utilize their ability. This kind of system aids in the organization and retrieval of information in sensory memory, just as a mnemonic device or code aids in semantic memory. It also has similar effects in that it extends the limits of sensory memory and incorporates more information than in usual conditions.

The present study represents a further examination of both the training methods designed by Cuddy and the categorization theory of Siegel. If the categorization process is to be accurate and efficient, the verbal labels and the qualities of the pitches they represent must be highly practiced. In the present study, an attempt was made to vary the familiarity factor by training the identification of out-of-tune pitches arranged in the form of a musical scale, with note names not used in Western musical notation. The questions considered were: (1) When AP possessors are given unpracticed and unfamiliar pitches, do they adapt their pitch categories to fit this system? (2) What strategies will the AP subjects use to learn this unfamiliar musical system and how will these strategies affect their performance? (3) Can this system be mastered both by AP possessors and nonpossessors? If so, what differences exist between the groups?

\section{METHOD}

\section{Subjects}

The subjects were eight students majoring in music at SUNY, Oneonta. Four claimed to possess AP. This was verified during the first experimental session when AP subjects correctly labeled all of 20 tones presented during a practice drill of the task, while control subjects performed at chance level and below. Subjects were volunteers and received no wages or credit for the task.

\section{Apparatus}

The stimuli for the task were sine-wave tones which had been generated by a Lafayette audio oscillator (Model WA44C) and amplifier (Model 1421). This unit was calibrated by a HewlettPackard electronic counter (Model 5221). Tones were recorded on Scotch 150 tape by a Lafayette tape recorder (Model 1775A) at $10 \mathrm{dBs}$ below standard $0 \mathrm{dBs}$ and were presented via MPC headphones (Model MX 200).

\section{Procedure}

The stimuli consisted of 13 tones covering a range between 349 and $698 \mathrm{~Hz}$, as shown in Table 1. The distance between tones was approximately 1 semitone (the distance separating tones on a musical scale), to correspond as closely as possible to the nature of a Western chromatic scale. Ten tones were set at frequencies that were midway between two pitches of the standard musical scale, so that they would normally be perceived as either very flat or very sharp. The tones were labeled with letters of the alphabet between $K$, the lowest pitch of the sequence, and $\mathrm{W}$, the highest pitch. The tones $\mathrm{K}$ and $\mathrm{W}$ corresponded precisely to the octaves $F$ and $F^{\prime}$, respectively, and the tone labeled $O$ corresponded precisely to $A$ at $440 \mathrm{~Hz}$, the stan- 
Table 1

Frequencies and Labels of Tones Used in Experiment in Relation to the Standard Musical Scale

\begin{tabular}{|c|c|c|c|c|c|c|c|c|c|c|c|c|c|}
\hline \multirow{3}{*}{$\begin{array}{l}\text { Labels } \\
\text { Hertz }\end{array}$} & \multirow{3}{*}{$\underset{349}{\mathrm{~K}}$} & \multicolumn{12}{|c|}{ Experimental Tones } \\
\hline & & $\mathbf{L}$ & $\mathbf{M}$ & $\mathbf{N}$ & 0 & $\mathbf{P}$ & $Q$ & $\mathbf{R}$ & $\mathbf{S}$ & $\mathrm{T}$ & $\mathrm{U}$ & $\mathrm{V}$ & $\begin{array}{c}\text { W } \\
608\end{array}$ \\
\hline & & 360 & 381 & 404 & 440 & 451 & 480 & 538 & 569 & 604 & 641 & 679 & \\
\hline & \multicolumn{13}{|c|}{ Musical Scale Tones } \\
\hline Labels & $\begin{array}{c}F \\
349\end{array}$ & $\begin{array}{l}\text { F\# } \\
370\end{array}$ & $\begin{array}{c}G \\
392\end{array}$ & $\begin{array}{r}\mathrm{G} \# \\
415\end{array}$ & $\begin{array}{c}A \\
440\end{array}$ & $\begin{array}{r}\text { A\# } \\
466\end{array}$ & $\begin{array}{c}\text { B } \\
494\end{array}$ & $\begin{array}{c}\mathrm{C} \\
523\end{array}$ & $\begin{array}{l}\mathrm{C} \# \\
554\end{array}$ & $\begin{array}{c}\mathrm{D} \\
587\end{array}$ & $\begin{array}{l}\mathrm{D \#} \\
622\end{array}$ & $\begin{array}{c}E \\
659\end{array}$ & $\begin{array}{l}F^{\circ} \\
698\end{array}$ \\
\hline
\end{tabular}

dard tuning pitch for musical instruments. These tones were included to see if subjects would recognize in-tune pitches in the context of an otherwise out-of-tune scale. Subjects were provided with a list of the tone labels and a schematic diagram of the tones as they would appear if scored on musical staff paper. These materials could be used throughout the experiment for reference.

Subjects were run individually in small, relatively noise-free rooms. Each subject was tested in three experimental sessions which were separated by at least 1 day. During each session, three training tape segments and one test tape segment were administered. Training segments consisted of, first, a presentation of the tones in ascending order, followed by 39 trials of pitch identification, during which tones were presented in random sequences, with the stipulation that each tone be presented three times and no two successive tones be the same. On each trial, a tone was presented for $1 \mathrm{sec}$, followed by $5 \mathrm{sec}$ of silence, during which the subject recorded on paper the name of the pitch, following which verbal feedback was given, i.e., the subject was given the correct name of the tone. Two seconds of silence separated the trials. Tests consisted of presentations of 39 trials of similar nature but with different random orderings, and with no feedback provided. The tests also did not include a presentation of the tones in ascending order prior to the onset of trials. Subjects were told they could rest between successive training and/or testing segments; otherwise, $15 \mathrm{sec}$ separated the segments.

\section{RESULTS AND DISCUSSION}

Percentage of correct responses was used to assess subjects' performance. Means for each group are presented in Figures 1 and 2 for testing and training scores, respectively. AP subjects outperformed controls on all

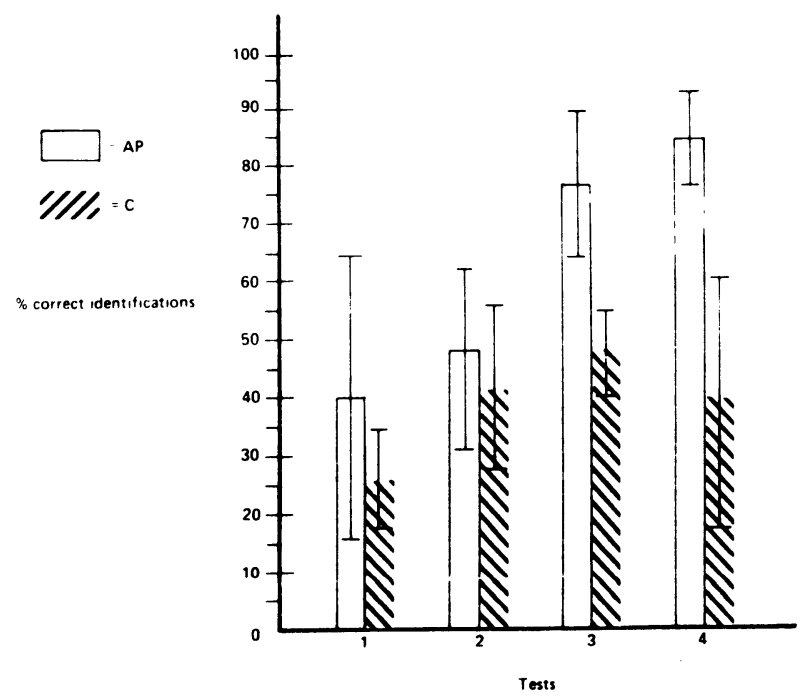

Figure 1. Means and standard deviations of test scores. trials in both testing and training conditions. The large standard deviations in the scores of the AP group on Test 1 and the $C$ group on Test 4 are due to the poor performance of one subject in the AP group and two subjects in the $\mathrm{C}$ group.

A 2 by 2 (Pitch by Trials) repeated-measures analysis of variance was performed to examine the differences between the groups. Results are given in Tables 2 and 3 for test and training scores, respectively. On test scores it was shown that the AP group performed better than controls. A similar effect was found for training scores. It was also found that both groups improved with practice on both test and training trials. Interactions of Pitch by Trials were not significant for either set of trials; both groups improved at approximately the same rate.

The strategies employed by the subjects are also of interest. Each AP subject arranged his or her own list or chart of the experimental tones and the most nearly corresponding standard musical pitches. These charts were used because subjects reported that the list provided for them was confusing and did not help them in learning the new scale. One subject consistently hummed the pitches as she listened, because she thought this helped her equate the two sets of pitches. Another AP subject began the task with the lowest score of either group, but eventually attained the highest score of $100 \%$ accuracy on Training Trial 8. She labeled the tones according to solfeggio, the $d o, m i$, sol system. The subjects apparently could identify the new scale only in relation to the learned and more familiar tones of the standard Western musical scale.

None of the AP subjects realized that three of the tones $(\mathrm{K}, \mathrm{O}$, and $\mathrm{W})$ were precisely in tune with the musical scale with which they were highly familiar. The tones $\mathrm{K}$ and $\mathrm{W}$ were learned quickly by both groups and were easily identified, no doubt, because they were the lowest and highest tones of the scale. However, many errors were made in identifying the tone $O$, and it was often labeled as $\mathrm{N}$ or $\mathrm{P}$, very likely because it was in the middle of the scale and more difficult to discriminate from its neighboring tones. An analysis of errors was performed on Training Trials 2 and 8 for both groups, and it was found that a very large percentage of the errors made were one-step errors, i.e., the tone was labeled either one step above or below its actual name.

All subjects reported that the identification task was easiest when two successive tones were adjacent notes on the scale. It was most difficult when the note to be 
Figure 2. Means and standard deviations of training scores.

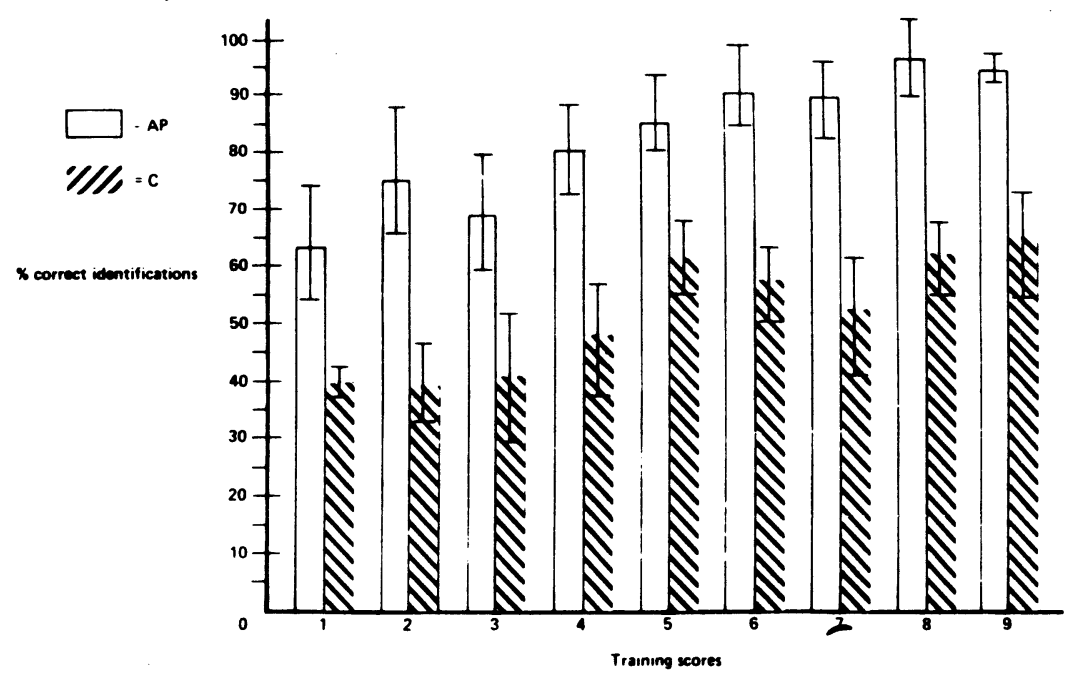

theory that AP possessors are superior in a pitch-naming task only when they can encode the stimuli verbally is also supported. This observation is notable because it relates the pitch frequency, which is nonverbal and relatively meaningless in itself, to its verbal label, which is part of a highly meaningful and easily remembered code. The code facilitates learning and retention by breaking down the broad continuum of pitch into smaller categories of octaves, intervals, and individual tones. A visual analog to this categorization process has been reported by Siegel and Siegel (1976), who demonstrated that subjects improved their memory for colors when provided with a verbal code.

It appears, then, that AP is an ability that can be acquired to some extent and that pitch information is subject to classification and organization, just as verbal information is in memory. The usual sequence of sensory memory appears to be enhanced for AP possessors by their apparent ability to internalize a pitch standard and retain it over long periods of time.

\section{REFERENCES}

Cuddy, L. L. Practice effects in the absolute judgment of pitch. Journal of the Acoustical Society of America, 1968, 43, 1069-1076.

CUDDY, L. L. Training the absolute indentfication of pitch. Perception \& Psychophysics, 1970, 8, 265-269.

Cuddy, L. L. Absolute judgment of musically-related pure tones. Canadian Journal of Psychology, 1971, 25, 42-55.

SIEGEI, J. A. The nature of absolute pitch. In I. E. Gordon (Ed.), Experimental research in the psychology of music (Vol. 8). lowa City: lowa University Press, 1972.

SIBGEL. J. A. Sensory and verbal coding strategies in subjects with absolute pitch. Journal of Experimental Psychology, 1974, 103, 37.44.

Sibgel, J. A., \& SIEGer, W. Absolute judgment and pairedassociate learning: Kissing cousins or identical twins? Psychological Review, 1972, 79, 300-316.

$10.37 *$

1.95 D. E. Improving memory for color. Bulletin of the Psychonomic Society, 1976, in press. 